\title{
Standardize Strawberry Crops by Applying the Quality Function Deployment in Huaura, Perú
}

\author{
Antonio Memenza ${ }^{1}$, Niels Cauty ${ }^{1}$, Fernando Sotelo, $\mathrm{MSc}^{1}$ and Edgar Ramos, $\mathrm{Mg}^{1}$ \\ 1'Ingeniería Industrial, Universidad Peruana de Ciencias Aplicadas, Perú, u201414483@upc.edu.pe, u201522800@upc.edu.pe, \\ pcinjsot@upc.edu.pe,pcineram@upc.edu.pe
}

\begin{abstract}
This research work seeks to propose the application of the QFD quality management tool in strawberry cultivation processes in the Huaura area. In the first instance, a review of the literature corresponding to the tool applied to agriculture is carried out, with which the quality control model for the strawberry production process is based. The hypothesis was established that the application of this quality control model will achieve the standardization of strawberry crops so that quality standards that allow export are achieved. A pilot implementation plan is proposed to corroborate the veracity of this hypothesis, selecting a particular type of strawberry, two farmers in the area and an implementation horizon of 8 months. It is expected to find the viability of this model to improve the quality of the strawberries of Huaura and the replicability of it to spread it in the region
\end{abstract}

Keywords-Quality deployment, Methodology, standardization, Strawberry crops.

\section{INTRODUCTION}

Agriculture is of great importance on the economy of various developing countries due to the contribution to internal production and employment, especially for less industrialized countries [1]. However, throughout the world, agriculture continues to face difficulties in its development. Underdeveloped countries are marginalized from international agricultural markets [2].

Despite all the economic opportunities attributed to globalization and international trade, small farmers generally not only cannot participate in international markets but also must compete with import products in their own internal markets [3].In these countries, a specific series of limitations are faced: Lack of credit, inadequate rural infrastructure, lack of technology and methodologies for proper agricultural development[4]. It is for these reasons that this article aims to apply the QFD quality control tool in order to standardize strawberry crops and thus return to the most competitive producers not only nationally but internationally.

Strawberry is one of the country's crops with good export potential and profitability that has not yet been fully exploited. Strawberries in Peru have the geographical conditions and the right climate to obtain final products of great international competitiveness. In recent years the cultivation of strawberries has been increasing in our territory occupying the 26th place of production during 2017.

According to studies, an introductory current diagnosis is given to strawberries in Peru, in which we can ask ourselves why the strawberry business in Peru has not yet taken off. The representative of Protunnel Mexico, mentions that the country has a magnificent climate and a privileged geographical position that would allow to go out to many markets having a fruit of better size and sweetness. He also mentions that the main cause has been the lack of vision and the little government support that farmers have had dedicated to this fruit.

In addition, he said "they have to overcome restrictions such as the low productivity of the agribusiness sector due to the obsolescence of technology and the lack of entrepreneurial capacity. They must take production when the countries of the northern hemisphere do not produce, that is when there is greater demand".

This article will aim to demonstrate that the adaptation and application of the characterization of processes in conjunction with the use of EFQM in the activities and processes of strawberry crops of small farmers in Huara will allow to standardize production and achieve quality standards in the product raising the volume suitable for export.

As shown in table I, the quality and standardization are the most important articles for this study, followed by agriculture and profitability.

TABLE I

\begin{tabular}{|l|l|}
\hline \multicolumn{2}{c}{ PAPER'S LIST } \\
\hline Topic & $\begin{array}{l}\text { Number of } \\
\text { papers }\end{array}$ \\
\hline 1. Quality Magnagment & 8 \\
\hline 2. Standarization & 6 \\
\hline 3. Profitability & 6 \\
\hline 4. Agriculture & 6 \\
\hline
\end{tabular}

\section{LITERATURE REVIEW}

A. Quality function deployment as a sustainable model

The QFD is a concept map that relates customer requirements (which we abbreviate $\mathrm{CR}$ ) with the technical characteristics (TC) necessary to satisfy them. These relationships are presented in the form of an elaborate table called "matrix of the quality ". Taken together, the CR define the quality of a product and the expressions that customers use to describe the products and their desirable features. Associated with each TC there is a metric, which is used to Determine the degree of customer satisfaction with each of your requirements is measure is essential for continuous improvement [5].

The main objectives of the QFD as a quality factor are to give priority to the expressed and latent needs of the customers with respect to a product, to translate those needs in terms of characteristics and technical specifications; and 
design, produce and deliver a quality product or service, focusing on customer satisfaction [6].

As we can see in Figure 1 there are a variety of aspects that impact on the methodology of QFD.

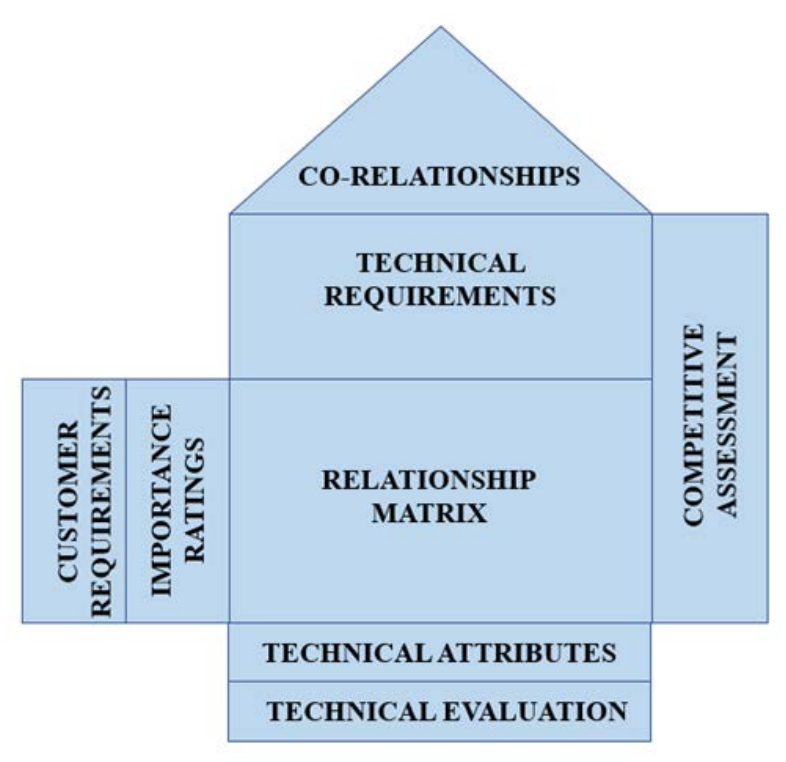

Fig. 1 Structure of house of quality

\section{B. Client requirements}

Customer requirements describe their needs, which are met by products or services. This is a reason to gather information, mainly through interviews [7]. Needs or requirements evolve over time and each change involves a cost[8]. That is why companies must ensure that they are aligned with the needs of customers through the use of management tools that allow them to collect and manage the information they provide [9].

As we can see in Figure 2 there is a strong relation between client satisfaction and the state of satisfaction. This are mainly related to external factors and basic factors [10].

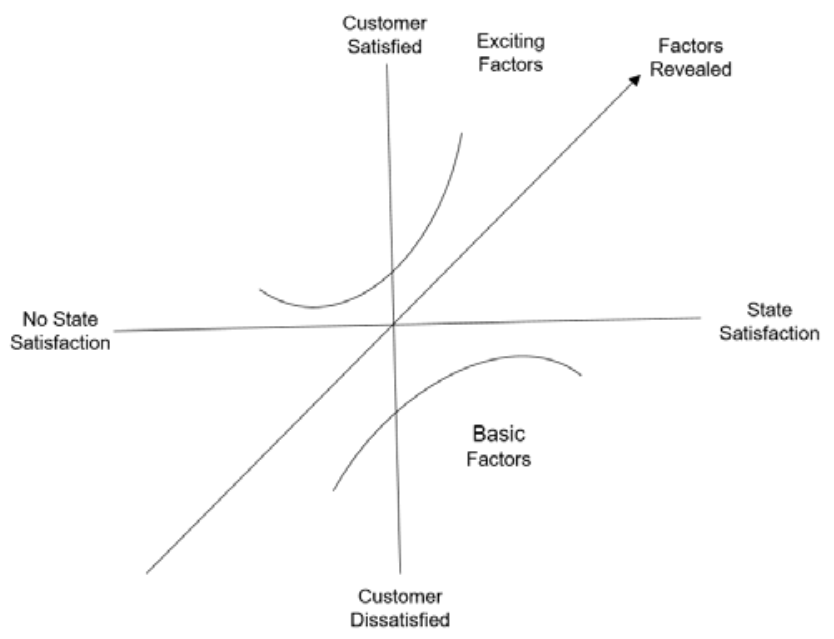

Fig. 2 Kano's satisfaction model

\section{METHODOLOGY}

\section{A. House of quality}

The quality house is one of the most important parts of the QFD, since it allows us to relate "the voice of the client" (its requirements or expectations) with the "voice of the engineer" and thus find the changes that must be made in the process design to reach the desired improvement. Its function is to present visually the relationships between different types of data [11].

This matrix is called "The house of quality" because it is intended to give an idea of lodging and shelter for the development of the process [12].

In summary, the analysis of the main problem led to the identification of five root causes within the processes of Quality Management, Production Planning and Control and Logistics Management. These root causes in question are shown below.

1) There are no control records of pesticide applications.

2) Farmers do not have long-term agreements with suppliers.

3) There are no resources needed for production under export standards.

4) Farmers do not plan their campaign production.

5) There is no association that provides technical support to farmers.

\section{B. Eight steps}

House of quality is made up of eight parts where the client wants to relate, how much of each requirement can be offered and how [13].

The eight steps are start by the "Whats" where customer requirements are determined. The following step is called the "Hows" and it is about finding the performance specifications needed to meet the customer's functional needs (the "whats"). Next, the "Whys" must be set as to explain the reason the product or service is necessary in the market. The fourth step is the "How much", in which it is estimated how much of the "Hows" is required to satisfy the "Whats". The next four steps are about establishing the relationship and correlation between the first four aspects described earlier.

In Figure 3 we can see that the variables mentioned a few lines above are strongly related to processes like product planning, part design process planning and finally production planning which take the outputs of the analysis in the previous one as their input in their own analysis.

This processes must be designed according to the necessities of clients and must be visible or acquire through the whole process of manufacture or in case of a service in the service provided[14]. 


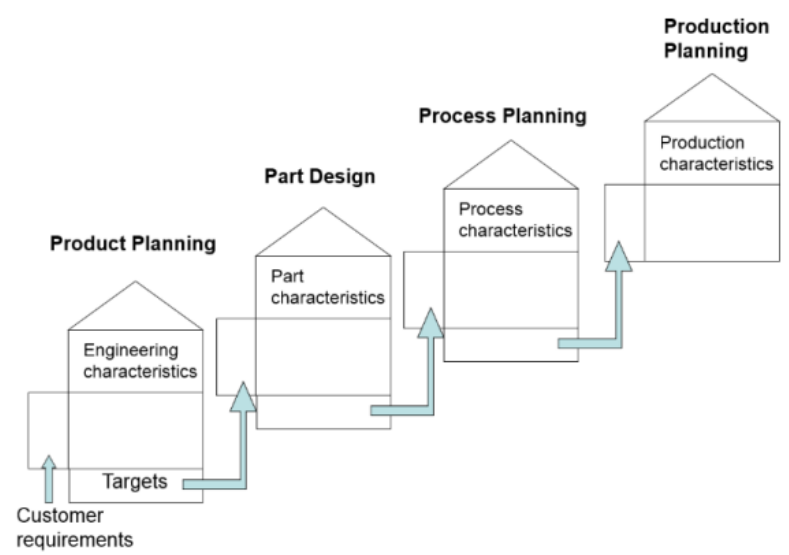

Fig. 3 Activities of QFD

\section{Modern QFD in agriculture}

Modern QFD appeared as a response to the limitation of its classic version, such as the number of matrices and tables that needed to be used in larger organizations. The main worry was to address an issue with agility and to choose the right problem to solve [15].

The original House of Quality is not enough to confront this matter and new tools are needed in order to keep improving design and development of products and to satisfy customer needs ultimately [16].

Modern QFD adapts Classical QFD and attains a system that allows to achieve quality over time for new or existing products [17]. The main requirements that are determined by Modern QFD can be easily analyzed using the Classical QFD matrices gaining agility and achieving better results [18].

Table 1 shows the main differences between Modern QFD and Classical QFD. It is clear how necessary was for Classical QFD to evolve into a new methodology in order to be competitive in such a changing environment as the current market is [19].

TABLE I

KEY DIFFERENCES BETWEEN CLASSIC AND MODERN QFD

\begin{tabular}{|l|l|}
\hline \multicolumn{1}{|c|}{ Classical QFD } & \multicolumn{1}{c|}{ Modern QFD } \\
\hline $\begin{array}{l}\text { Use of House of Quality } \\
\text { mainly }\end{array}$ & $\begin{array}{l}\text { Variety of tools, including former } \\
\text { ones such as the House of Quality }\end{array}$ \\
\hline $\begin{array}{l}\text { Oriented to understanding or } \\
\text { comprehension of needs }\end{array}$ & $\begin{array}{l}\text { Oriented not only to meet customer } \\
\text { needs, but to do it with agility and } \\
\text { efficiency }\end{array}$ \\
\hline $\begin{array}{l}\text { Focus on many problems } \\
\text { without addressing the most } \\
\text { critical }\end{array}$ & $\begin{array}{l}\text { Use voice of customer as the key to } \\
\text { address the most important needs of } \\
\text { the clients }\end{array}$ \\
\hline
\end{tabular}

The Modern QFD can be applied in different businesses due to its dynamicity, the way that it would be applied in agriculture is going to be described in the following lines [20]. First the farmer must identify the expectations of the final client that in this case is the wholesaler. These must include the minimum international standards needed to be met for a product to be exportable.
Then, before the matrix of quality is used to identify what can be done to reach those expectations, the requirements initially identified must be prioritized, focusing first on what the farmers must attain in as an urgent matter [21].

For the development of the management model, the EFQM was used as a reference, which is a model of excellence that serves for self-evaluation and identification of processes that have opportunities for improvement.

This model is made up of three main elements within which are the values of excellence that describe the pillars that every organization should consider to achieve sustainable excellence, the criteria provided by regulations to help organizations convert the concepts of the EFQM in something applicable and finally the REDER logical scheme that is a tool that is used to drive the improvements throughout the organization [22].

For this investigation, the application of some of the values of excellence will be carried out:

1) Add value for customers: Farmers will constantly add value by understanding export requirements.

2) Develop the capacity of the organization: Farmers will increase their management capacity to manage their fields so that they become more efficient.

3) Lead with vision, inspiration and integrity: Farmers will lead the staff in charge of sowing and harvesting, which requires leadership capacity.

4) Achieve success through people's talent: Farmers will identify valuable talent within the planting and harvesting staff so that there is not so much rotation.

5) Maintain outstanding results over time: This value is one of the most important, since once a high level of quality has been achieved, it must be maintained over time.

These values will be reflected in all quality processes and will be disseminated through the training that will be carried out. Below is the detail of the subprocesses belonging to Quality Management, which have been characterized by developing the flow chart, SIPOC diagram and indicator sheets corresponding to this subprocess. The respective procedural manuals are found as complementary accompanying documents.

\section{RESULTS}

What is expected to be obtained with the application of the QFD methodology in the strawberry cultivation process in the district of Huaura is the standardization of its processes and, therefore, the standardization of its product so that it can be exported.

Perform the planning of the human and material resources that the project will require, so that these resources are then provisioned and conditioned. Finally, awareness and training is carried out, which consists of carrying out awareness campaigns, the preparation and dissemination of the new functions that farmers will perform, the simulation of the process improves and absolves doubts, the evaluation and 
reinforcement of the knowledge of the improved process and the validation and adjustment of formats and documents.

Once all these activities are completed, the start-up of the process begins, where the first activity is the monitoring and verification that consists of the attention of queries and doubts of the process, the review of incidents and doubts about the activities and procedures and the collection of data and records.

Likewise, during the last weeks where the previously mentioned activities are carried out, the adjustments and improvements of the process will also be carried out, where there will be a review of the incidents and indicators, consolidation of adjustment or improvement initiatives, adjustment and validation of process flow and awareness and training of changes.

Having completed the implementation of the processes, the stabilization of these processes begins, where the documents and records are formalized, and a validation of the process changes is carried out. With this activity the project is completed.

TABLE II

RESULTS OF THE IMPLEMENTATION

\begin{tabular}{|l|l|l|}
\multicolumn{1}{|c|}{ RESULTS OF THE IMPLEMENTATION } \\
\hline $\begin{array}{l}\text { Concept } \\
\text { Number of } \\
\text { strawberries }\end{array}$ & $\begin{array}{c}\text { Base value - Before } \\
\text { implementation }\end{array}$ & $\begin{array}{c}\text { Collected values - } \\
\text { After implementation }\end{array}$ \\
\hline Product shrinkage & $23 \%$ boxes / hectare & 355 boxes / hectare \\
\hline $\begin{array}{l}\text { Product suitable } \\
\text { for export }\end{array}$ & $20 \%$ & $14 \%$ \\
\hline $\begin{array}{l}\text { Response time to } \\
\text { pests and diseases }\end{array}$ & 15 days & $86 \%$ \\
\hline Sale to processor & Could not be sold & Can be sold \\
\hline
\end{tabular}

Regarding the level of implementation with respect to technology, the following considerations were taken:

1) Irrigation was by sprinklers instead of drip irrigation.

2) A cover canvas was used.

3) No pipes, hoses or pump were used for irrigation and applications.

Regarding procedures, standards and good practices, the following points were covered:

1) Application of land preparation schedule

2) Ground curing

3) Quality inspection (Routine)

4) Collection and cleaning (harvest)

5) Insecticide application according to schedule

6) Weed according to schedule

7) Filling of records and records
To validate the effectiveness and value of the proposal for planning and control of production, the values resulting from interviewing farmers in the area are taken as a reference point.

Likewise, farmers are expected to increase their income, as export sales generate an average of $60 \%$ more profitability compared to national sales.

Finally, it is expected to diversify the model to different areas of Peruvian agriculture, as it is part of one of the country's primary activities.

In summary, the results of the implementation have had positive impacts on the most important aspects raised in the research, see Table 2. However, in a larger-scale application these could be reduced a little because the control that was exhausted was exhaustive.

In this chapter the provenance and reliability of the sources of information used in this research work was verified, confirming that all the articles consulted were published in indexed journals and within the range of the last five years. In addition, it was validated that the objectives set for each chapter of this thesis were fulfilled, which served as a base guide for the development of this work.

Even more important, the results were presented and the implementation pilot that led them was detailed, showing improvements in production volume and product standards. Likewise, this chapter covers the validation of the model by the users based on their experience in the commissioning of the pilot; for which a validation matrix was designed and the results found were analyzed.

Finally, the expected impacts on different aspects of the farmers' context are raised, such as associativity, education, better prices, higher yields, lower costs, land pollution and land erosion.

A matrix was made to evaluate the expected impacts in the social, economic and environmental spheres in relation to quality processes, logistics and production planning and control. Next, it will be detailed what each of the aforementioned areas covers.

\section{A. Social}

This factor is subdivided into associativity and education. Associativity refers mainly to the willingness of farmers to consolidate a group, whether temporary or permanent, that allows them to achieve competitiveness in terms of volume and quality of strawberry production. Regarding the education factor, it refers mainly to the acquisition of knowledge that farmers can achieve through the implementation of the proposed methodology.

\section{B. Economic}

This factor is subdivided into prices, performance and costs. When prices refer mainly to the sales value of strawberries for export, which may vary depending on the quality and volume to be sold. The yield refers to the amount of strawberry that can be harvested per hectare of land, which can vary depending mainly on the methods used to grow. 
Finally, costs refer to all expenses incurred during a campaign to grow strawberries.

\section{Environmental}

This factor is subdivided into pollution and soil erosion. Land contamination occurs when solid waste is found in it. As for the erosion of the land it refers to the degradation of the soil that is given by the type of irrigation.

\section{Social Impact}

The result obtained in the social impact is 4.33 which means that it has a strong positive impact. This result reinforces the idea that the implementation of the methodology is rooted in the association of farmers to have better results. As far as education is concerned, the result is also high with a score of 4.0 , which reinforces the idea that involved farmers will increase their knowledge in order to obtain better results when growing.

\section{E. Economic impact}

The score obtained in the price subdivision is 3.67, which would mean that it does not have a very significant impact. However, this is because the farmers' profit will be reflected not so much by the variation in the price but by the volume of sale. Regarding the yield, a score of 4.0 was obtained, which indicates that increasing the yield per hectare generates a positive impact. Finally, the costs obtained a score of 3.67, which reflects a moderately significant positive impact. It is also worth mentioning that the higher the number of associated farmers, the impact on costs will increase, as better prices will be obtained for purchases.

\section{F. Environmental impact.}

In terms of environmental impacts, both the contamination of the land and its erosion obtained an almost neutral result. This is mainly due to the fact that the proposal is not closely linked to the environmental factor. However, it should be mentioned that the result tends to have a positive impact.

Therefore, based on this analysis, it can be concluded that the implementation proposal is sustainable and favorable for users in different aspects of their socio-economic context.

\section{CONCLUSIONS}

QFD, either Classical or Modern, has not been used widely in the agriculture industry. Rural farmers, such as strawberry farmers from Huaura, need simple, but powerful tools that can help them organize and achieve quality in their products. This work can be the opening gate to further investigations with the goal to implement QFD methodology in agriculture and help farmers increase their level of exportable product.
Exploratory pilots should be conducted in order to gain information and test what is asserted this time, as well as to improve this first model.

The irrigation method used by $95 \%$ of farmers in the area is known as flooding. Although this method implies less effort and cost, it also means a greater wear of the earth and the drag of the nutrients present in it. If we add to this the fact that more than $75 \%$ of farmers only pay the land once per campaign, without considering the superficial applications that are carried out later, the result is a reduction in the yield of significant crops.

Thus, it is necessary to use technology such as irrigation and drip applications to achieve a production greater than $30 \%$ compared to the conventional method of gravity or flood irrigation. It is evident that there is great potential for improvement only with this change in the activities of strawberry crops.

Farmers in the area agree that the pesticides that are allowed for the cultivation of strawberries to be exported are very expensive. Thus, only 35\% of these farmers use these products. In addition, of those farmers who work with exporters, $10 \%$ fail to comply with these requirements and incur sanctions or even at the end of the commercial relationship.

The exporting companies offer technical training in the use of pesticides allowed during the campaign; however, only half of the invited farmers are the ones who finally attend, this because they prioritize their daily work in the crop. Furthermore, there is no control or registration of pesticide applications in crops. Thus, in addition to working methods, the use of pesticides and pesticides also does not follow established standards, specifically for export, resulting in obtaining a product not suitable for the international market.

Likewise, the technique and frequency with which the harvests are carried out can be different between crops, resulting in a production range from 320 to 400 beans of fruits harvested per hectare in a sweep. Translated into kilograms of product, there is a difference between productions in the area of approximately $400 \mathrm{~kg}$ among farmers due to the nonstandardization of working methods.

With the dissemination and application of good practices both at work and in pesticide applications during the pilot implementation plan, an increase from $20 \%$ to $56 \%$ of exportable product was achieved and a reduction of productive decline from $23 \%$ to a $14 \%$ Likewise, the farmer users who were part of the implementation positively rated the proposed improvement in product standardization. Thus, the adoption of good practices and compliance with pesticide standards proved necessary to obtain a uniform and suitable product for exportations.

\section{REFERENCES}

[1] FAO, World fertilizer trends and outlook to 2018

[2] Z. Raziei, S. A. Torabi, S. Tabrizian, y B. Zahiri, "A Hybrid GDMSERVQUAL-QFD Approach for Service Quality Assessment in Hospitals”, EMJ - Eng. Manag. J., 2018. 
[3] L. Frizziero, D. Francia, G. Donnici, A. Liverani, y G. Caligiana, "Sustainable design of open molds with QFD and TRIZ combination", J. Ind. Prod. Eng., 2018.

[4] M. Fargnoli y T. Sakao, "Uncovering differences and similarities among quality function deployment-based methods in Design for $\mathrm{X}$ : Benchmarking in different domains”, Qual. Eng., 2017.

[5] F. Franceschini y D. Maisano, "Prioritization of QFD Customer Requirements Based on the Law of Comparative Judgments”, Qual. Eng., 2015.

[6] T. J. Howard, T. Eifler, S. N. Pedersen, S. M. Göhler, S. M. Boorla, y M. E. Christensen, "The variation management framework (VMF): A unifying graphical representation of robust design”, Qual. Eng., 2017.

[7] Y. Prasetyawan y A. H. Santosa, "Manufacturing process design for multi commodities in agriculture”, en AIP Conference Proceedings, 2017.

[8] M. Fargnoli, M. Lombardi, y N. Haber, "A fuzzy-QFD approach for the enhancement of work equipment safety: A case study in the agriculture sector”, Int. J. Reliab. Saf., 2018.

[9] I. Alsyouf, U. Kumar, L. Al-Ashi, y M. Al-Hammadi, "Improving baggage flow in the baggage handling system at a UAE-based airline using lean Six Sigma tools”, Qual. Eng., 2018.

[10]R. Salehzadeh, A. Shahin, A. Kazemi, y A. S. Barzoki, "Is organizational citizenship behavior an attractive behavior for managers? A Kano model approach”, J. Manag. Dev., 2015.

[11]N. Li, C. Laux, y J. Antony, "Designing for Six Sigma in a private organization in China under TQM implementation: A case study”, Qual. Eng., 2018.

[12]G. Donnici, L. Frizziero, D. Francia, A. Liverani, y G. Caligiana, "Innovation design driven by QFD and TRIZ to develop new urban transportation means”, Aust. J. Mech. Eng., 2019.

[13]F. Franceschini y D. Maisano, "A new proposal to improve the customer competitive benchmarking in QFD”, Qual. Eng., 2018.

[14]G. Bartholomé, S. Lecheler, y C. de Vreese, "Manufacturing Conflict? How Journalists Intervene in the Conflict Frame Building Process”, Int. J. Press., 2015.

[15]S. Erdem, G. Özdağoğlu, y O. Yilmaz, "Developing a new product via modern QFD: An application for bedding of laboratory animals”, en International Journal of Product Development, 2016.

[16]M. Ashrafuzzaman, A. Al-Maruf, I. M. Mahbubul, A. B. M. A. Malek, y A. M. M. Mukaddes, "Quality function deployment approach to measure supply chain performance: A case study on garments accessories industries”, Int. J. Ind. Syst. Eng., 2016.

[17]P. Pitayachaval, K. Chittrakool, y W. Arjharn, "Integration of Business Model Canvas (BMC) and Quality Function Deployment (QFD) to design product”, en 2017 4th International Conference on Industrial Engineering and Applications, ICIEA 2017, 2017.

[18]I. G. Cristea y D. Mocuta, “Customer relationship management”, en Proceedings of the 31st International Business Information Management Association Conference, IBIMA 2018: Innovation Management and Education Excellence through Vision 2020, 2018.

[19]N. B. Ocampo Jimenez y R. Baeza Serrato, "Effectiveness of QFD in a municipal administration process”, Bus. Process Manag. J., 2016.

[20]M. Yazdani, P. Chatterjee, E. K. Zavadskas, y S. Hashemkhani Zolfani, "Integrated QFD-MCDM framework for green supplier selection”, J. Clean. Prod., 2017.

[21]N. Kuswardhani, M. Misbahudin, y B. H. Purnomo, "Physical quality improvement of coffee Robusta (Coffee robusta Lindl) in Argopuro Mountain, Jember”, en IOP Conference Series: Earth and Environmental Science, 2019.

[22]A. Calvo-Mora, A. Navarro-García, and R. Periañez-Cristobal, "Project to improve knowledge management and key business results through the EFQM excellence model,” Int. J. Proj. Manag., 2015.

18 $^{\text {th }}$ LACCEI International Multi-Conference for Engineering, Education, and Technology: "Engineering, Integration, and Alliances for a Sustainable Development” "Hemispheric Cooperation for Competitiveness and Prosperity on a Knowledge-Based Economy”, 29-31 July 2020, Buenos Aires, Argentina. 